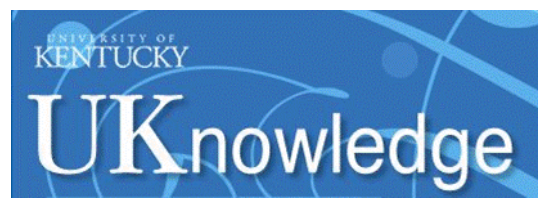

University of Kentucky

UKnowledge

\title{
Evaluation of a Community-Based Positive Youth Development Program in Hong Kong: Views of Program Implementers
}

\author{
Daniel T. L. Shek \\ University of Kentucky \\ Cecilia M. S. Ma \\ The Hong Kong Polytechnic University, China \\ Xiaoqin Zhu \\ The Hong Kong Polytechnic University, China
}

Follow this and additional works at: https://uknowledge.uky.edu/pediatrics_facpub

Part of the Child Psychology Commons, Chinese Studies Commons, Community-Based Learning Commons, and the Developmental Psychology Commons

Right click to open a feedback form in a new tab to let us know how this document benefits you.

\section{Repository Citation}

Shek, Daniel T. L.; Ma, Cecilia M. S.; and Zhu, Xiaoqin, "Evaluation of a Community-Based Positive Youth Development Program in Hong Kong: Views of Program Implementers" (2017). Pediatrics Faculty Publications. 278.

https://uknowledge.uky.edu/pediatrics_facpub/278

This Article is brought to you for free and open access by the Pediatrics at UKnowledge. It has been accepted for inclusion in Pediatrics Faculty Publications by an authorized administrator of UKnowledge. For more information, please contact UKnowledge@lsv.uky.edu. 


\section{Evaluation of a Community-Based Positive Youth Development Program in Hong Kong: Views of Program Implementers}

\section{Digital Object Identifier (DOI)}

https://doi.org/10.1515/ijdhd-2017-7006

\section{Notes/Citation Information}

Published in International Journal on Disability and Human Development, v. 16, issue 4, p. 377-385.

(C2017 Walter de Gruyter GmbH, Berlin/Boston.

The copyright holder has granted the permission for posting the article here. 


\section{Daniel T.L. Shek*, Cecilia M.S. Ma and Xiaoqin Zhu}

\section{Evaluation of a community-based positive youth development program in Hong Kong: views of program implementers}

DOI 10.1515/ijdhd-2017-7006

Received July 17, 2016; accepted August 18, 2016; previously published online January 26, 2017

Abstract: Using a subjective outcome evaluation method, the current study investigated program implementers' perceptions of the Tier 1 Program of the community-based P.A.T.H.S. Project in Hong Kong. After completion of the program, 599 program implementers completed a valid and reliable scale (i.e. Form $B$ ) to give their ratings on program content, their own performance, and perceived program effectiveness. As expected, most program implementers perceived the program in a favorable way by giving very positive ratings on the three aspects measured in Form B. Grade differences on the ratings were observed, with implementers teaching the senior curriculum held more positive views on program effectiveness than did those teaching the junior curriculum. Similar to previous findings, perceived program content and perceived worker performance predicted program effectiveness. Findings of the present study provide further evidence for the success of the Tier 1 Program of the community-based P.A.T.H.S. Project in Hong Kong.

Keywords: client satisfaction; Hong Kong; Project P.A.T.H.S., positive youth development; subjective outcome evaluation.

\section{Introduction}

It is well known around the world that school success is morbidly emphasized in Chinese societies. Because of the

\footnotetext{
*Corresponding author: Daniel T.L. Shek, Associate Vice President and Chair Professor of Applied Social Sciences, Department of Applied Social Sciences, The Hong Kong Polytechnic University, Hung Hom, Hong Kong, P.R. China; Centre for Innovative Programmes for Adolescents and Families, The Hong Kong Polytechnic University, Hong Kong, P.R. China; School of Social Development, East China Normal University, Shanghai, P.R. China; Kiang Wu Nursing College of Macau, Macau, P.R. China; and Division of Adolescent Medicine, Department of Pediatrics, Kentucky Children's Hospital, University of Kentucky School of Medicine, Lexington, KY, USA, E-mail: daniel.shek@polyu.edu.hk Cecilia M.S. Ma and Xiaoqin Zhu: Department of Applied Social Sciences, The Hong Kong Polytechnic University, Hong Kong, P.R. China
}

traditional Chinese belief that educational success leads to financial success and social status [1], Chinese students are expected by themselves and significant others such as parents, teachers, and relatives to perform well in school and study hard to achieve high grades and academic excellence [2, 3]. Such a strong emphasis on academic achievement is further intensified by the filial piety orientation in the collectivistic Chinese culture. Specifically, achieving school success is regarded as children's responsibility to their parents, and children's failure in school study may generate shame for the whole family [4]. As a result, Chinese students usually experienced more academic stress than did their Western counterparts [5].

In Hong Kong, student performance at one learning stage determines their chance to study in an outstanding school in the following stage. Hence, students are struggling to survive and stand out in an educational environment characterized by intense competition and rigid selection, even early from kindergarten to higher education $[6,7]$. For example, students need to sit for public examinations prior to entering higher education. Although, the new "334” education schema (i.e. 3 years of junior secondary education, 3 years of senior secondary education, and 4 years of undergraduate education) implemented since the academic year of 2009/2010 reduced the number of public examinations from two to one, the new secondary school curriculum posed extra challenges for adolescents. For example, "Liberal Studies" became a core subject (i.e. all students need to take this subject) under the new curriculum where students have to work much harder and exert extra effort [8].

With the above-mentioned circumstances, it is not surprising to find that over $45 \%$ of students regarded their studies as stressful, and even a larger proportion (i.e. $50.3 \%$ ) of students felt pressure regarding the new curriculum [9]. It is noteworthy that academic pressure experienced during adolescence can cause mental illness or other risk behavior. For example, a growing body of evidence suggested that academic pressure placed on adolescents was positively related to their anxiety and depression symptoms [3, 10, 11]. Besides, school-related stress such as school performance felt by students during secondary school was positively associated with hopelessness [12] but 
inversely related to well-being $[11,12]$. An even serious consequence of the high level of academic stress was increased adolescent suicide ideation [13, 14]. In fact, the time in a year when the number of suicide cases peaked paralleled with the examination periods when there was a considerable increase in the academic stress of students [14].

Apart from the high level of pressure to excel in school, adolescents also face other challenges that result from pubertal change during adolescence. As a transitional phase from childhood to adulthood, adolescence is marked by a range of physiological, cognitive, psychological, emotional, and social changes, which could be potentially stressful [15]. The stress resulting from these inevitable developmental changes makes adolescents especially vulnerable to develop a variety of problem behaviors, such as Internet addiction, substance abuse, sexual issues, school bullying, gambling, and delinquent acts. For example, $21.1 \%$ of secondary school adolescents in Iran showed problematic symptoms of Internet use [16]. Among German students aged between 12 and 25 years, approximately $25 \%, 21 \%$, and $6.4 \%$ of respondents reported current smoking, alcohol use, and cannabis use, respectively [17]. In Taiwan, in a sample containing 2119 youth aged 20 years, over $15 \%$ of them reported premarital sex experience when they were teenagers [18].

With respect to adolescent developmental problems in Hong Kong, researchers noted a rising and worrying trend of substance abuse, Internet addiction, premarital sex, school bullying, and material orientation [19]. Recent studies revealed that the prevalence of these problem behaviors still remained at a high level. For example, $\mathrm{Yu}$ and Shek [20] reported that over one-fifth of school adolescents displayed Internet addiction symptoms. In addition, Narcotics Division [21] showed that $2.3 \%$ of the middle school students and $2.5 \%$ of post-secondary students took drugs. Although the percentage of Hong Kong adolescents attempting suicide (4\%) was not high and was lower than the figures reported in other areas, quite a high proportion of adolescents manifested self-harm [22]. In particular, research showed that more than $23 \%$ of junior secondary school students had ever engaged in deliberate self-harm behavior (e.g. direct cutting and scratching) in the past 12 months [22]. This prevalence rate of self-harm is higher than that of mainland China adolescents, where nearly $17 \%$ committed self-harm during the past 12 months [23].

Considerable attention has been paid to adolescent problem behavior because of its high prevalence and significant negative influence on adolescent well-being and developmental outcomes. For example, Bradley and Greene [24] reviewed studies published between 1985 and 2010 to highlight associations between academic achievement and six types of risk behaviors in adolescents, including tobacco use, violence, drug (including alcohol) use, unprotected sexual activities, unhealthy dietary behaviors, and lack of physical activity. They found that $96.6 \%$ of the studies they reviewed reported significant and negative associations between adolescent risk behavior and academic performance. With the upsurge of adolescent problem behaviors and their long-standing negative impact on youth development [25], some scholars stated that it is especially important to promote adolescent positive youth development (PYD) attributes, which can help them maintain healthy functioning and cope with school distress and pubertal changes in an adaptive way $[19,26]$.

Different from traditional prevention approaches that focus on dealing with a single problem such as smoking or drinking, the PYD perspective highlights positive and bright sides of adolescents and regards adolescents as "resources to be developed" ([27], p. 172). More specifically, the PYD approach emphasizes developmental assets and highlights adolescents' all-round healthy functioning in various domains, such as resilience, social and emotional competence, moral competence, and cognitive competence [28, 29]. Accordingly, the aim of PYD programs is to prevent a variety of adolescent problems through promoting their positive development rather than to deal with one single problem at a time. The underlying philosophy is that adolescents will be less likely to develop problem behaviors if they are equipped with strong psychosocial competencies. This idea is similar to the belief in Chinese medicine, if the body is strong enough, symptoms of illness will not easily develop [19].

There is extensive evidence demonstrating that PYD programs are effective in strengthening adolescent competence and preventing adolescent risk behavior. For example, Catalano et al. [26] showed that well-evaluated universal, selective, and indicated PYD programs in different countries (e.g. USA, Australia, European countries, and Hong Kong) significantly enhanced participants' psychosocial competencies and educational attainment, while at the same time reduced their alcohol use, drug abuse, risky sexual activity, aggression and delinquency, crime, and depression. In Hong Kong, the most notable PYD program was the one entitled "Positive Adolescent Training through Holistic Social Programmes" (i.e. Project P.A.T.H.S.), which was designed by Shek and his collaborators to strengthen PYD qualities (i.e. multiple psychosocial competencies) in junior secondary school students (i.e. Grade 7 to 9) [30, 31].

The Project P.A.T.H.S. has two tiers of programs. The Tier 1 Program is a curricula-based universal program for 
students in all grade levels, and it was developed upon 15 PYD constructs (e.g. bonding, social and emotional competence, clear and positive identity, self-efficacy, and beliefs in the future) proposed by Catalano et al. [28] after reviewing the critical components of effective PYD programs. The Tier 2 Program is a selective program designed for those students with greater psychosocial needs, such as those students having family problems. With financial support from The Hong Kong Jockey Club Charities Trust, The Project P.A.T.H.S. has been successfully implemented from 2005/2006 school year till present. From 2005/2006 to $2011 / 2012$ school years, the project was implemented in the school context. A series of rigorous evaluation studies revealed a great success of the project as reflected by the high level of client satisfaction by different stakeholders, and enhanced competencies and reduced problem behaviors in the program participants [32-35].

Due to the remarkable success of the first 7 years of implementation, the project was further transformed from a school-based model to a community-based model commencing at 2013. In this phase, a number of non-governmental organizations (NGOs) providing service to children and youth were responsible for recruiting students and implementing the project. A community-based model of PYD program implementation has its own strengths. For example, previous studies showed that implementation fidelity was higher in community-based contexts than that in a school-based model [36]. One possible reason is that youth workers in communities such as social workers in NGOs may be more experienced than school teachers in implementing youth program materials. Besides, community-based delivery of the program will not be constrained by school time and arrangement of other courses or activities. As a result, programs run by NGOs can also involve students from schools that did not join the Project P.A.T.H.S., by inviting these students to apply by themselves.

According to existing evaluation studies [37-40], the first 2 years of community-based implementation of the Project P.A.T.H.S. was as effective as previous schoolbased implementation. To replicate these findings and to examine whether the third year (i.e. 2015) implementation was as smooth and effective as that in previous 2 years, we adopted the subjective outcome evaluation approach, which is also known as the client satisfaction approach to investigate program implementers' experience. Subjective outcome evaluation has been widely used in human service settings such as education, rehabilitation, counseling, and social work. This approach is convenient and efficient in revealing clients' views toward a program, which could further indicate the effectiveness of program implementation. Furthermore, some studies have shown that client satisfaction with the program was closely associated with findings of objective outcome evaluation, such as participant improvement in terms of enhanced PYD competencies [41, 42].

The present study focused on the Tier 1 Program of the Project P.A.T.H.S. implemented in 2015 by looking at program implementers' evaluation of the program, which could inform strengths, weaknesses, and directions of future improvement of the program [39]. In previous studies, program implementers usually showed positive evaluations on the Tier 1 Program regarding the program content, their own performance, and program effectiveness [39, 43]. In addition, program implementers' evaluation of program effectiveness could be significantly predicted by their perceptions of program content and their own performance. However, inconsistent findings were also reported in the area of grade differences in subjective outcome evaluation ratings. For example, Sun and Shek [43] found that implementers teaching junior students reported more positive evaluations in all aspects than did those teaching senior students. However, such a grade difference was not observed in other studies [39, 44]. Based on these findings, the present study attempted to address the following questions and hypotheses:

1. How did implementers perceive the community-based Tier 1 Program implemented in 2015? Based on previous studies, positive evaluations were expected (H1).

2. Did implementers teaching different grades have different evaluations? Given the inconsistent findings in previous studies, we did not make specific hypotheses regarding this research question.

3. Were there any significant relationships among implementers' perceptions of program content, instructor performance, and effectiveness of the program? Based on previous findings, we hypothesized that evaluation of program effectiveness would be significantly related to program content (H2a) and implementers' performance (H2b). We also expected that program content (H3a) and implementers' performance (H3b) would be significant predictors of perceived effectiveness of the program.

\section{Methods}

In the third year of the community-based P.A.T.H.S. Project (i.e. 2015), there were 72 Tier 1 programs implemented by 21 agencies. Among these programs, 40,18, and 13 were implemented at Secondary 1 (S1), Secondary 2 (S2), and Secondary 3 (S3) level, respectively, with the remaining one program involving students from more than one 
grade. These programs were implemented by 713 teachers, social workers, and/or program workers, with 531, 108, and 73 implementers teaching S1, S2, and S3 curriculum, respectively. The number of implementers across all programs ranged between 1 and 35, with a mean of $9.90(S D=7.61)$. Over half of the programs $(n=37,51.39 \%)$ were taught by both teachers and social workers, while $44.44 \%$ $(\mathrm{n}=32)$ of the programs were taught by social workers only and three programs ( $4.17 \%)$ were taught by teachers only. Regarding the implementation settings, a total of 65 programs $(90.28 \%)$ were delivered in schools, while four programs $(5.56 \%)$ were conducted in community centers and three programs (4.17\%) were implemented in both settings.

To evaluate the effectiveness of the Tier 1 Program, program implementers were invited to respond to a scale named as "Subjective Outcome Evaluation Form for Instructors” (i.e. Form B) after completion of the program. A total of 599 implementers completed Form B, resulting in an overall response rate of $82.99 \%$. An evaluation manual with detail guidelines on collection and analyses of Form B data were given to the implementers.

\section{Instruments}

The Form B used in the current study was a valid and reliable measure and has been widely used in previous evaluation studies [41, 44]. This measure consisted of both quantitative and qualitative questions. However, the present study only focused on quantitative data due to space limitation. Quantitative questions assessed implementers' views via three subscales: program content (10 items), implementer performance (10 items), and program effectiveness (16 items). As shown in Table 1, these three subscales had good reliability in the present study with Cronbach's $\alpha$ above 0.90. In addition to these three subscales, three other items measured implementers' willingness to suggest other students to join the program (one item), willingness to work as instructors in similar programs in future (one item), and the extent to which the program was helpful for personal growth (one item). For subscales of program content and implementer performance, a 6-point scale was used while a 5-point scale was adopted for program effectiveness subscale. For all items, higher scores indicated more positive evaluations.

\section{Data analyses}

In the present study, individual data of the implementers were used as basic units of analysis. Firstly, we performed reliability analyses for the three subscales (i.e. program content, implementers' performance, and program effectiveness) of Form B. Then, descriptive statistical analyses were carried out to indicate the percentage of positive responses regarding implementer perceptions of different aspects of the Tier 1 Program. To examine differences in implementers' evaluations across different grade levels, a multivariate analysis of variance (MANOVA) was further conducted, with grade as the independent variable and implementers' evaluations on three subscales as dependent variables. Correlations amongst implementers' evaluations on different aspects of the program were investigated using Pearson correlation analyses. Several multiple regression analyses were conducted to examine whether evaluations of program content and program implementers' performance significantly predicted perceived program effectiveness across the three grade levels.

\section{Results}

Numbers and percentages of implementers having positive evaluations of the Tier 1 Program on the different domains of the scale are shown in Tables 2-5. Overall speaking, implementers had positive evaluations on all aspects. As a result, Hypothesis 1 was supported. As shown in Table 2, implementers' views toward program content were overall positive, with over $90 \%$ of the implementers giving positive ratings on all the 10 items across all grade levels. In addition, most implementers agreed that "the design of the curriculum is very good" (93.5\%) and "the classroom atmosphere was very pleasant" $(96.2 \%)$, and $92.8 \%$ of the implementers had very positive views of the program. For implementers' own performance, most implementers also reported favorable evaluations (Table 3). More specifically, $98.2 \%$ of implementers had very positive evaluations of themselves, and $99 \%$ of them thought that they cared for the students, and over $98 \%$ of implementers regarded themselves as "having good professional attitudes", "very involved", and "ready to offer help to students when needed".

Similar positive results were found for the perceived effectiveness of the program. As demonstrated in Table 4, more than $96 \%$ of implementers endorsed that the program promoted students' overall development. Most implementers also indicated that the program

Table 1: Reliability analyses and correlations among implementers' perceptions on different aspects.

\begin{tabular}{|c|c|c|c|c|}
\hline \multirow[t]{2}{*}{ Subjective outcome evaluation scales } & \multirow{2}{*}{$\begin{array}{r}\text { Cronbach's } \\
\alpha\end{array}$} & \multirow{2}{*}{$\begin{array}{r}\text { Mean inter-item } \\
\text { correlation }\end{array}$} & \multicolumn{2}{|r|}{ Inter-scale correlation } \\
\hline & & & Program content & Program implementers \\
\hline Program content (10 items) & 0.92 & 0.55 & - & \\
\hline Implementers' performance (10 items) & 0.93 & 0.59 & $0.73^{\mathrm{a}}$ & \\
\hline Program effectiveness (16 items) & 0.94 & 0.52 & $0.55^{\mathrm{a}}$ & $0.49^{\mathrm{a}}$ \\
\hline
\end{tabular}

${ }^{\mathrm{a} p}<0.001$ 
Table 2: Summary of the program implementers' positive perceptions toward the program content.

\begin{tabular}{|c|c|c|c|c|c|c|c|c|}
\hline & \multicolumn{8}{|c|}{ Respondents with positive responses (Options 4-6) } \\
\hline & \multicolumn{2}{|r|}{ S1 } & \multicolumn{2}{|r|}{$\mathbf{S 2}$} & \multicolumn{2}{|r|}{ S3 } & \multicolumn{2}{|c|}{ Overall } \\
\hline & $\mathbf{n}$ & $\%$ & $\mathbf{n}$ & $\%$ & $\mathbf{n}$ & $\%$ & $\mathbf{n}$ & $\%$ \\
\hline 1. The objectives of the curriculum are very clear & 443 & 97.6 & 78 & 97.5 & 63 & 98.4 & 585 & 97.7 \\
\hline 2. The design of the curriculum is very good & 422 & 93.0 & 76 & 95.0 & 61 & 95.3 & 560 & 93.5 \\
\hline 3. The activities were carefully planned & 430 & 94.7 & 77 & 96.3 & 63 & 98.4 & 571 & 95.3 \\
\hline 4. The classroom atmosphere was very pleasant & 433 & 95.4 & 78 & 97.5 & 64 & 100.0 & 576 & 96.2 \\
\hline 5. There was much peer interaction amongst the students & 426 & 93.8 & 79 & 98.8 & 62 & 96.9 & 568 & 94.8 \\
\hline $\begin{array}{l}\text { 6. Students participated actively during lessons (including } \\
\text { discussions, sharing, games, etc.) }\end{array}$ & 428 & 94.3 & 76 & 95.0 & 61 & 95.3 & 566 & 94.5 \\
\hline 7. The program has a strong and sound theoretical support & 424 & 93.4 & 74 & 92.5 & 63 & 98.4 & 562 & 93.8 \\
\hline $\begin{array}{l}\text { 8. The teaching experience I encountered enhanced my interest } \\
\text { toward the lessons }\end{array}$ & 416 & 91.6 & 73 & 91.3 & 62 & 96.9 & 552 & 92.2 \\
\hline 9. Overall speaking, I have a very positive evaluation of the program & 420 & 92.5 & 73 & 91.3 & 62 & 96.9 & 556 & 92.8 \\
\hline 10. On the whole, students like this curriculum very much & 421 & 92.7 & 75 & 93.8 & 62 & 96.9 & 559 & 93.3 \\
\hline
\end{tabular}

All items were rated on a 6-point Likert scale with $1=$ strongly disagree, $2=$ disagree, $3=$ slightly disagree, $4=$ slightly agree, $5=$ agree, $6=$ strongly agree. Only respondents with positive responses (Options 4-6) are shown in the table.

S1, Secondary 1 level; S2, Secondary 2 level; S3, Secondary 3 level.

Table 3: Summary of the program implementers' positive perceptions toward their own performance.

\begin{tabular}{|c|c|c|c|c|c|c|c|c|}
\hline & \multicolumn{8}{|c|}{ Respondents with positive responses (Options 4-6) } \\
\hline & \multicolumn{2}{|r|}{ S1 } & \multicolumn{2}{|r|}{ S2 } & \multicolumn{2}{|r|}{ S3 } & \multicolumn{2}{|c|}{ Overall } \\
\hline & $\mathrm{n}$ & $\%$ & $\mathrm{n}$ & $\%$ & $\mathrm{n}$ & $\%$ & $\mathrm{n}$ & $\%$ \\
\hline 1. I have a good mastery of the curriculum & 436 & 96.0 & 78 & 97.5 & 62 & 96.9 & 577 & 96.3 \\
\hline 2. I prepared well for the lessons & 436 & 96.0 & 78 & 97.5 & 63 & 98.4 & 578 & 96.5 \\
\hline 3. My teaching skills were good & 437 & 96.3 & 78 & 97.5 & 64 & 100.0 & 580 & 96.8 \\
\hline 4. I have good professional attitudes & 446 & 98.2 & 80 & 100.0 & 64 & 100.0 & 591 & 98.7 \\
\hline 5. I was very involved & 444 & 97.8 & 79 & 98.8 & 64 & 100.0 & 588 & 98.2 \\
\hline 6. I gained a lot during the course of instruction & 422 & 93.0 & 76 & 95.0 & 60 & 93.8 & 559 & 93.3 \\
\hline 7. I cared for the students & 448 & 98.7 & 80 & 100.0 & 64 & 100.0 & 593 & 99.0 \\
\hline 8. I was ready to offer help to students when needed & 448 & 98.7 & 80 & 100.0 & 62 & 96.9 & 591 & 98.7 \\
\hline 9. I had much interaction with the students & 436 & 96.0 & 78 & 97.5 & 62 & 96.9 & 577 & 96.3 \\
\hline 10. Overall speaking, I have a very positive evaluation of myself as an instructor & 445 & 98.0 & 78 & 97.5 & 64 & 100.0 & 588 & 98.2 \\
\hline
\end{tabular}

All items were reported on a 6-point Likert scale with $1=$ strongly disagree, $2=$ disagree, $3=$ slightly disagree, $4=$ slightly agree, $5=$ agree, $6=$ strongly agree. Only respondents with positive responses (Options 4-6) are shown in the table. S1, Secondary 1 level; S2, Secondary 2 level; S3, Secondary 3 level.

strengthened students' resilience (95.7\%), social competence (97.8\%), ability to distinguish good and bad (97.0\%), and competence in making wise choices (96.0\%). Table 5 shows implementers' ratings on the additional three questions. Over $90 \%$ of the participants indicated that they were willing to suggest other students to participate in the program $(94.8 \%)$ and teach similar programs in future (93.2\%). Besides, nearly 95\% of the implementers thought the program helped to promote their personal growth.

The results of MANOVA are depicted in Table 6. Grade differences were not observed for implementers' evaluations of program content and their own performance.
However, a significant grade difference was found for perceived program effectiveness $[F(2,573)=5.06$, $\left.\mathrm{p}=0.007, \eta_{\mathrm{p}}^{2}=0.02\right]$. Post-hoc analyses revealed that implementers teaching Secondary 3 students $(M=3.93$, $S D=0.53)$ perceived higher program effectiveness than did those teaching Secondary 1 students $(M=3.69$, $S D=0.55, \mathrm{p}=0.005)$.

The correlation coefficients among evaluations of program content, performance of the implementers, and effectiveness of the program are shown in Table 1. Consistent with our hypotheses (i.e. H2a and $\mathrm{H} 2 \mathrm{~b}$ ), program content quality $(r=0.55, \mathrm{p}<0.001)$ and implementer 
Table 4: Summary of the program implementers' positive perceptions toward the program effectiveness.

\begin{tabular}{|c|c|c|c|c|c|c|c|c|}
\hline & \multicolumn{8}{|c|}{ Respondents with positive responses (Options 3-5) } \\
\hline & \multicolumn{2}{|r|}{ S1 } & \multicolumn{2}{|r|}{ S2 } & \multicolumn{2}{|r|}{ S3 } & \multicolumn{2}{|c|}{ Overall } \\
\hline & $\mathbf{n}$ & $\%$ & $\mathbf{n}$ & $\%$ & $\mathbf{n}$ & $\%$ & $\mathbf{n}$ & $\%$ \\
\hline $\begin{array}{l}\text { 1. It has strengthened students' bonding with teachers, classmates, } \\
\text { and their families }\end{array}$ & 425 & 93.6 & 74 & 92.5 & 60 & 93.8 & 560 & 93.5 \\
\hline 2. It has strengthened students' resilience in adverse conditions & 436 & 96.0 & 73 & 91.3 & 63 & 98.4 & 573 & 95.7 \\
\hline 3. It has enhanced students' social competence & 446 & 98.2 & 76 & 95.0 & 63 & 98.4 & 586 & 97.8 \\
\hline $\begin{array}{l}\text { 4. It has improved students' ability in handling and expressing } \\
\text { emotions }\end{array}$ & 439 & 96.7 & 74 & 92.5 & 62 & 96.9 & 576 & 96.2 \\
\hline 5. It has enhanced students' cognitive competence & 430 & 94.7 & 74 & 92.5 & 62 & 96.9 & 567 & 94.7 \\
\hline 6. Students' ability to resist harmful influences has been improved & 428 & 94.3 & 73 & 91.3 & 60 & 93.8 & 562 & 93.8 \\
\hline $\begin{array}{l}\text { 7. It has strengthened students' ability to distinguish between the } \\
\text { good and the bad }\end{array}$ & 442 & 97.4 & 77 & 96.3 & 61 & 95.3 & 581 & 97.0 \\
\hline $\begin{array}{l}\text { 8. It has increased students' competence in making sensible and wise } \\
\text { choices }\end{array}$ & 439 & 96.7 & 73 & 91.3 & 62 & 96.9 & 575 & 96.0 \\
\hline 9. It has helped students to have life reflections & 415 & 91.4 & 71 & 88.8 & 60 & 93.8 & 547 & 91.3 \\
\hline 10. It has reinforced students' self-confidence & 429 & 94.5 & 76 & 95.0 & 64 & 100.0 & 570 & 95.2 \\
\hline 11. It has increased students' self- awareness & 440 & 96.9 & 77 & 96.3 & 64 & 100.0 & 582 & 97.2 \\
\hline 12. It has helped students to face the future with a positive attitude & 432 & 95.2 & 77 & 96.3 & 63 & 98.4 & 573 & 95.7 \\
\hline $\begin{array}{l}\text { 13. It has helped students to cultivate compassion and care about } \\
\text { others }\end{array}$ & 423 & 93.2 & 73 & 91.3 & 59 & 92.2 & 556 & 92.8 \\
\hline 14. It has encouraged students to care about the community & 396 & 87.2 & 65 & 81.3 & 55 & 85.9 & 517 & 86.3 \\
\hline $\begin{array}{l}\text { 15. It has promoted students' sense of responsibility in serving the } \\
\text { society }\end{array}$ & 400 & 88.1 & 67 & 83.8 & 53 & 82.8 & 521 & 87.0 \\
\hline 16. It has enriched the overall development of the students & 437 & 96.3 & 76 & 95.0 & 64 & 100.0 & 578 & 96.5 \\
\hline
\end{tabular}

All items were reported on a 5-point Likert scale with $1=$ unhelpful, $2=$ not very helpful, $3=$ slightly helpful, $4=$ helpful, $5=$ very helpful. Only respondents with positive responses (Options 3-5) are shown in the table. S1, Secondary 1 level; S2, Secondary 2 level; S3, Secondary 3 level.

Table 5: Summary of the program implementers' positive perceptions toward other aspects.

\begin{tabular}{|c|c|c|c|c|c|c|c|c|}
\hline \multirow[t]{2}{*}{ Items } & \multicolumn{2}{|r|}{ S1 } & \multicolumn{2}{|r|}{ S2 } & \multicolumn{2}{|r|}{ S3 } & \multicolumn{2}{|c|}{ Overall } \\
\hline & $n$ & $\%$ & $\mathrm{n}$ & $\%$ & $n$ & $\%$ & $\mathrm{n}$ & $\%$ \\
\hline Willingness to suggest other students to participate in the programa & 428 & 94.3 & 75 & 93.8 & 64 & 100 & 568 & 94.8 \\
\hline Willingness to teach similar programs in future ${ }^{a}$ & 418 & 92.1 & 77 & 96.3 & 62 & 96.9 & 558 & 93.2 \\
\hline The extent to which the program helped implementers' personal growth ${ }^{\mathrm{b}}$ & 424 & 93.4 & 77 & 96.3 & 62 & 96.9 & 564 & 94.2 \\
\hline
\end{tabular}

S1, Secondary 1 level; S2, Secondary 2 level; S3, Secondary 3 level.

${ }^{a}$ A 4-point Likert scale was used, with $1=$ definitely will not, 2 =will not, $3=$ will, $4=$ definitely will. Only respondents with positive responses (Options 3-4) are shown in the table.

${ }^{b}$ A 5-point Likert scale was used, with $1=$ unhelpful, $2=$ not very helpful, $3=$ slightly helpful, $4=$ helpful, $5=$ very helpful. Only respondents with positive responses (Options 3-5) are shown in the table.

Table 6: Comparisons of implementers' subjective outcome evaluation on different aspects across grades.

\begin{tabular}{|c|c|c|c|c|c|c|c|c|}
\hline & \multicolumn{2}{|c|}{$S 1(n=437)$} & \multicolumn{2}{|c|}{$S 2(n=76)$} & \multicolumn{2}{|c|}{$S 3(n=63)$} & \multicolumn{2}{|c|}{ MANOVA } \\
\hline & $M$ & $S D$ & $M$ & $S D$ & $M$ & $S D$ & $\boldsymbol{F}$ & $p \eta^{2}$ \\
\hline Program content (10 items) & 4.70 & 0.60 & 4.73 & 0.56 & 4.84 & 0.43 & 1.92 & 0.007 \\
\hline Implementers' performance (10 items) & 4.85 & 0.57 & 4.91 & 0.48 & 5.02 & 0.49 & 2.72 & 0.009 \\
\hline Program effectiveness (16 items) & 3.69 & 0.55 & 3.74 & 0.54 & 3.93 & 0.53 & $5.06^{\mathrm{a}}$ & 0.017 \\
\hline
\end{tabular}

S1, Secondary 1 level; S2, Secondary 2 level; S3, Secondary 3 level.

${ }^{\mathrm{a}} \mathrm{p}<0.01$. 
Table 7: Multiple regression analyses predicting perceived program effectiveness by perceptions on program content and implementers' performance.

\begin{tabular}{|c|c|c|c|c|}
\hline & \multicolumn{2}{|r|}{$\beta$} & \multirow[t]{2}{*}{$\boldsymbol{F}$} & \multirow[t]{2}{*}{$\mathbf{R}^{2}$} \\
\hline & $\begin{array}{r}\text { Program } \\
\text { content }\end{array}$ & $\begin{array}{l}\text { Implementers' } \\
\text { performance }\end{array}$ & & \\
\hline Secondary 1 & $0.40^{\mathrm{a}}$ & $0.21^{\mathrm{a}}$ & $101.48^{\mathrm{a}}$ & 0.32 \\
\hline Secondary 2 & $0.61^{\mathrm{a}}$ & 0.01 & $22.01^{\mathrm{a}}$ & 0.36 \\
\hline Secondary 3 & $0.32^{b}$ & 0.25 & $11.37^{\mathrm{a}}$ & 0.25 \\
\hline Overall & $0.42^{\mathrm{a}}$ & $0.19^{\mathrm{a}}$ & $137.59^{\mathrm{a}}$ & 0.32 \\
\hline
\end{tabular}

${ }^{\mathrm{a}} \mathrm{p}<0.001 ;{ }^{\mathrm{b}} \mathrm{p}<0.05$

performance $(r=0.49, \mathrm{p}<0.001)$ were both positively associated with perceived program effectiveness.

According to multiple regression analyses (Table 7), both perceived program content $(\beta=0.40, \mathrm{p}<0.001)$ and worker performance $(\beta=0.21, \mathrm{p}<0.001)$ were significant predictors of perceived program effectiveness at Secondary 1 level. However, only perceived program content significantly predicted perceived program effectiveness at Secondary $2(\beta=0.61, \mathrm{p}<0.001)$ and Secondary 3 $(\beta=0.32, \mathrm{p}<0.05)$ levels, whereas worker performance did not have significant predicting effect at these two grade levels. For the whole dataset, both evaluations of program content $(\beta=0.42, \mathrm{p}<0.001)$ and implementer performance $(\beta=0.19, \quad \mathrm{p}<0.001) \quad$ significantly predicted perceived program effectiveness. This overall model accounted for $32 \%$ of the variance of perceived program effectiveness. As a result, Hypothesis $3 a$ was supported at each grade level and the whole dataset, while Hypothesis $3 \mathrm{~b}$ was supported at Secondary 1 level and the whole sample.

\section{Discussion}

The present research attempted to replicate previous evaluation findings regarding implementers' perceptions of the Tier 1 Program of the community-based Project P.A.T.H.S. in Hong Kong. To do this, the present study utilized a valid and reliable measure of subjective outcome evaluation to assess the implementers' views on several aspects, including program content, implementer performance, program effectiveness, willingness to recommend the program to other students, willingness to teach similar programs in future, and whether the implementation experience helped promote implementers' personal growth. These measures not only helped to explore implementers' evaluation in a comprehensive way but also allowed us to further clarify the factors contributing to perceived program effectiveness. Besides, a large sample was used in the present study ( $\mathrm{n}=599)$, which enhanced the generalizability of present findings to the populations.

Overall speaking, for the community-based Tier 1 Program implemented in 2015, the implementers held positive perceptions of the program. For example, the implementers perceived the program content positively: approximately $98 \%$ of them considered that curriculum objectives were clear, nearly $94 \%$ perceived the curriculum was well designed, and over $95 \%$ agreed that the activities were meticulously designed. Besides, the implementers held favorable views toward their own performance. Over $95 \%$ of the program implementers regarded themselves as caring, willing to help students, and well prepared for the lessons. These findings are largely in line with previous evaluation findings $[39,44]$.

The implementers also perceived the Tier 1 Program as effective in promoting different areas of development in the students, including resilience, social competence, cognitive competence, self-awareness, social responsibility, and ability in distinguishing good and bad. Noteworthy, most implementers (over 90\%) were willing to suggest other students to join the program and teach similar programs in future, and nearly $95 \%$ of the implementers thought the program increased their personal growth. Together with previous findings $[38,39]$, the positive results found in the present study suggest that the Project P.A.T.H.S. is quite successful in Hong Kong no matter in which context (i.e. school or community) it is implemented. As the increase in adolescents' PYD qualities would promote adaptability and well-being as well as reduce adolescent problem behaviors $[9,45,46]$, the Project P.A.T.H.S. with an objective to promote adolescents' PYD competencies is regarded as a timely and effective means of minimizing negative influences of high academic pressure and extensive developmental challenges on Hong Kong adolescents.

In the current study, we did not find grade differences in implementers' evaluations of program content and their own performance. These results are in line with most of the previous studies which also did not find grade differences in implementers' subjective outcome evaluation $[39,44]$. The results suggest that programs for all grades were well designed and all implementers were well engaged regardless of intended grades. However, one unique finding in the present study was that implementers teaching senior form (i.e. Secondary 3 level) rated the program as more effective than did implementers teaching junior form (i.e. Secondary 1 level). This result is quite different from previous findings, in that some studies found similar ratings for program effectiveness among 
implementers in different grades [39, 44], and one study found lower ratings for program effectiveness among implementers in senior grades compared with perceived program effectiveness in junior grades [43]. On one hand, the present finding suggests that students in senior grades were not necessarily less interested in and worse engaged in the program, just as some studies found that students in higher grades had better perceptions of PYD programs than did students in lower grades [40]. On the other hand, as the number of implementers in different grades varied a lot, and the sample size of the present study was smaller than that of Sun and Shek's [43] study, the present finding needs to be replicated in future studies using a larger sample size and more balanced sub-samples in different grades.

Theories and empirical studies suggested that there were five salient factors contributing to the effectiveness of PYD programs: program, people, policy, place, and process (i.e. 5P model) [47]. The present study considered two factors: "program" (i.e. program content) and "people" (i.e. implementers). Congruent with this 5P model and similar to previous studies [44], the present study showed that evaluations on program content and implementer performance were both positively associated with perceived program effectiveness. These findings supported Hypotheses 2a and 2b. In addition, multiple regression analyses indicated that both evaluations of program content and worker performance were significant predictors of perceived program effectiveness in the whole sample. Hence, Hypothesis $3 \mathrm{a}$ and Hypothesis $3 \mathrm{~b}$ were also supported. However, perceived program content significantly predicted perceived program effectiveness in all grade levels, while perceived implementer quality only showed a significant effect on Secondary 1 grade. One possible reason may be due to the small sub-sample size on Secondary 2 and 3 grades. Hence, further research with a larger sample size at each grade level is in need to elucidate the present finding.

The current study has several limitations. First, although subjective outcome evaluation approach has its own advantages, it suffers from inherent limitations, such as systematic biases result from item order, psychological factors, and macroeconomic fluctuations [48]. Therefore, findings should be interpreted with caution, and future studies could include both objective and subjective measures to test program effectiveness. Second, the present study was quantitative in nature. Qualitative designs such as focus group interview should be further included to present a more comprehensive picture of the Project P.A.T.H.S. implemented in the community contexts. Lastly, only two factors (i.e. program and people) of the 5P model were considered as potential predictors of program effectiveness in the present study. Thus, it is hard to identify other contributing factors and explore interactions among these factors. It will certainly be illuminating to take into account more factors that would affect program success.

Despite these limitations, the present study showed that program implementers were highly satisfied with the Tier 1 Program of the Project P.A.T.H.S. implemented based on the community contexts in 2015. More specifically, both program content and implementers' performance got extremely good ratings. In addition, the program implementers perceived that both students and they themselves benefited a lot from the program. Together with previous evaluation findings, the present study again suggests that the Project P.A.T.H.S. can effectively promote holistic development in Hong Kong adolescents.

Acknowledgments: The present article and the Project P.A.T.H.S. are financially supported by the Hong Kong Jockey Club Charities Trust.

\section{References}

1. Hesketh T, Ding QJ. Anxiety and depression in adolescents in urban and rural China. Psychol Rep 2005;96:435-44.

2. Shek DT, Chan LK. Hong Kong Chinese parents' perceptions of the ideal child. J Psychol 1999;133:291-302.

3. Quach AS, Epstein NB, Riley PJ, Falconier MK, Fang X. Effects of parental warmth and academic pressure on anxiety and depression symptoms in Chinese adolescents. J Child Fam Stud 2015;24:106-16.

4. Triandis HC, McCusker C, Hui CH. Multimethod probes of individualism and collectivism. J Pers Soc Psychol 1990;59:1006-20.

5. Liu Y, Lu Z. The Chinese high school student's stress in the school and academic achievement. Educ Psychol 2011;31:27-35.

6. Kwan Y. Life satisfaction and self-assessed health among adolescents in Hong Kong. J Happiness Stud 2010;11:383-93.

7. Jaffee D. The general education initiative in Hong Kong: organized contradictions and emerging tensions. High Educ 2012;64:193-206.

8. Chan CK, Luk LY. Faculty perspectives on the " $3+3+4$ " curriculum reform in Hong Kong: a case study. Int Educ Stud 2013;6:56-66.

9. Shek DT, Leung H. Perceived family quality of life, school competence, and academic adjustment among early adolescents in Hong Kong. In: Shek DT, Sun RC, Ma CM, editors. Chinese Adolescents in Hong Kong. Singapore: Springer, 2014:71-91.

10. Liu Y, Lu Z. Chinese high school students' academic stress and depressive symptoms: gender and school climate as moderators. Stress Health 2012;28:340-6.

11. Moksnes UK, Løhre A, Lillefjell M, Byrne DG, Haugan G. The association between school stress, life satisfaction and depressive symptoms in adolescents: life satisfaction as a potential mediator. Soc Indic Res 2016;125:339-57. 
12. Shek DT, Li X. Perceived school performance, life satisfaction, and hopelessness: a 4-year longitudinal study of adolescents in Hong Kong. Soc Indic Res 2016;126:921-34.

13. Ang RP, Huan VS. Relationship between academic stress and suicidal ideation: testing for depression as a mediator using multiple regression. Child Psychiatr Hum Dev 2006;37:133-43.

14. Ung E. Youth suicide and parasuicide in Singapore. Ann Acad Med Singapore 2003;32:12-8.

15. Moksnes UK, Byrne DG, Mazanov J, Espnes GA. Adolescent stress: evaluation of the factor structure of the adolescent stress questionnaire (ASQ-N). Scand J Psychol 2010;51:203-9.

16. Ahmadi K, Saghafi A. Psychosocial profile of Iranian adolescents' Internet addiction. Cyberpsychol Behav Soc Netw 2013;16:543-8.

17. Walther B, Morgenstern M, Hanewinkel R. Co-occurrence of addictive behaviours: personality factors related to substance use, gambling and computer gaming. Eur Addict Res 2012;18:167-74.

18. Chiao C, Yi C-C, Ksobiech K. Exploring the relationship between premarital sex and cigarette/alcohol use among college students in Taiwan: a cohort study. BMC Public Health 2012;12:527.

19. Shek DT, Keung Ma H, Sun RC. A brief overview of adolescent developmental problems in Hong Kong. ScientificWorld] 2011;11:2243-56.

20. Yu L, Shek DT. Internet addiction in Hong Kong adolescents: a three-year longitudinal study. J Pediatr Adolesc Gynecol 2013;26:S10-7.

21. Narcotics Division. The $2014 / 15$ survey of drug use among students. URL: http://www.nd.gov.hk/en/survey_of_drug_use_1415.htm.

22. Law BM, Shek DT. Self-harm and suicide attempts among young Chinese adolescents in Hong Kong: prevalence, correlates, and changes. J Pediatr Adolesc Gynecol 2013;26:S26-32.

23. Wan Y-H, Hu C-L, Hao J-H, Sun Y, Tao F-B. Deliberate self-harm behaviors in Chinese adolescents and young adults. Eur Child Adolesc Psychiatry 2011;20:517-25.

24. Bradley BJ, Greene AC. Do health and education agencies in the United States share responsibility for academic achievement and health? a review of 25 years of evidence about the relationship of adolescents' academic achievement and health behaviors. J Adolesc Health 2013;52:523-32.

25. Pergamit MR, Huang L, Lane J. The long term impact of adolescent risky behaviors and family environment. URL: http://aspe. hhs.gov/execsum/long-term-impact-adolescent-risky-behaviors-and-family-environment.

26. Catalano RF, Fagan AA, Gavin LE, Greenberg MT, Irwin CE, Ross DA, et al. Worldwide application of prevention science in adolescent health. Lancet 2012;379:1653-64.

27. Lerner RM, Dowling EM, Anderson PM. Positive youth development: Thriving as the basis of personhood and civil society. Appl Dev Sci 2003;7:172-80.

28. Catalano RF, Berglund ML, Ryan JA, Lonczak HS, Hawkins JD. Positive youth development in the United States: research findings on evaluations of positive youth development programs. Ann Am Acad Polit Soc Sci 2004;591:98-124.

29. Lerner RM. Liberty: thriving and civic engagement among American youth, 1st ed. Thousand Oaks, CA: Sage, 2004.

30. Shek DT, Sun RC. The Project P.A.T.H.S. in Hong Kong: development, training, implementation, and evaluation. J Pediatr Adolesc Gynecol 2013;26:S2-9.
31. Shek DT, Sun RC, editors. Development and evaluation of Positive Adolescent Training through Holistic Social Programs (P.A.T.H.S.). Singapore: Springer, 2013.

32. Shek DT, Ma CM. Impact of the Project PATHS in the junior secondary school years: individual growth curve analyses. ScientificWorldJ 2011;11:253-66.

33. Shek DT, Yu L. Impact of the Project PATHS on adolescent risk behavior: a five-year longitudinal study. In: Shek DT, Sun RC, editors. Development and evaluation of Positive Adolescent Training through Holistic Social Programs (P.A.T.H.S.). Singapore: Springer, 2013:85-106.

34. Shek DT, Sun RC. Positive youth development programs for adolescents with greater psychosocial needs: subjective outcome evaluation over 3 years. J Pediatr Adolesc Gynecol 2014;27: S17-25.

35. Shek DT, Yu L, Ho VY. Subjective outcome evaluation and factors related to perceived effectiveness of the project P.A.T.H.S. in Hong Kong. ScientificWorldJ 2012;2012:Article 490290.

36. Fagan AA, Hanson K, Hawkins JD, Arthur MW. Implementing effective community-based prevention programs in the Community Youth Development Study. Youth Violence Juv Justice 2008;6:256-78.

37. Shek DT, Zhu X, Wu FK. Subjective outcome evaluation of the community-based program of the P.A.T.H.S. project in Hong Kong. Int J Child Adolesc Health, in press.

38. Shek DT, Liang RL, Ma CM. Subjective outcome evaluation of the community-based project P.A.T.H.S. in Hong Kong. Int J Child Adolesc Health, in press.

39. Shek DT, Ng CS, Law MY. Community-based positive youth development program in Hong Kong: views of the program implementers. Int J Adolesc Med Health 2016. DOI: 10.1515/ ijamh-2017-3003. [Epub ahead of print].

40. Shek DT, Law MY. Evaluation of programs for adolescents with greater psychosocial needs: community-based P.A.T.H.S. Project in Hong Kong. Int J Adolesc Med Health, in press.

41. Shek DT. Is subjective outcome evaluation related to objective outcome evaluation? Insights from a longitudinal study in Hong Kong. J Pediatr Adolesc Gynecol 2014;27:S50-6.

42. Shek DT. Subjective outcome and objective outcome evaluation findings: insights from a Chinese context. Res Soc Work Pract 2010;20:293-301.

43. Sun RC, Shek DT. Perceived program qualities and outcomes of a youth program in Hong Kong based on the views of the workers. J Pediatr Adolesc Gynecol 2014;27:S10-6.

44. Shek DT, Pu X, Leung JT, Law MY. Subjective outcome evaluation of the community-based P.A.T.H.S. project: views of program implementers. Int J Child Adolesc Health, in press.

45. Sun RC, Shek DT. Longitudinal influences of positive youth development and life satisfaction on problem behaviour among adolescents in Hong Kong. Soc Indic Res 2013;114:1171-97.

46. Shek DT, Liang J. Risk factors and protective factors in substance abuse in Chinese adolescents in Hong Kong. In: Lee TY, Shek DT, Sun RC, editors. Student well-being in Chinese adolescents in Hong Kong: theory, intervention and research. Singapore: Springer, 2015:237-53.

47. Shek DT, Sun RC. Implementation of a positive youth development program in a Chinese context: The role of policy, program, people, process, and place. ScientificWorldJ 2008;8:980-96.

48. Jahedi S, Méndez F. On the advantages and disadvantages of subjective measures. J Econ Behav Organ 2014;98:97-114. 